\title{
Impact assessment on the performance of e-learning in corporate training programs in the context of globalization
}

\author{
Roxana Maria GAVRIL \\ The Bucharest University of Economic Studies, Bucharest, Romania \\ roxana.gavril@gmail.com \\ Jan KIEHNE \\ The Bucharest University of Economic Studies, Bucharest, Romania
}

Christian Richard HELL

The Bucharest University of Economic Studies, Bucharest, Romania

\section{Carsten KIRSCHNER}

The Bucharest University of Economic Studies, Bucharest, Romania

\begin{abstract}
The goal of this paper is to identify the main criteria based on which e-Learning is used in organizational development with positive impact on business performance. Globalization has led to a multitude of changing markets, including learning and education. While quality production systems are implemented based on imposed standards, the business knowledge of employees varies in each country, mirroring the education system provided locally. The results are individually different knowledge gaps which challenged the learning industry to develop new strategies embedded in e-learning solutions. Major contribution to theory and practice on combining vision and spoken learning is brought by the work of psychologists and professors of education (Allen, 2012; Mayer, 2009; Hattie, 2009). Their innovations offered solutions for easy access to knowledge and implementation methods, as well as the documentation of the inclusion of videos in e-learning modules (Halls, 2012), offering teachers and trainers the possibility to create a live experience to trainees engaged in e-learning programs. This paper is based on data collected internationally and our empirical research undertaken in Romania, which is Europe's main cluster for various production industries and world's second for IT. Based on a questionnaire, we interviewed 18 multinational companies which perform parts of their business activities in Romania. Research results show that with the implementation of an effective e-learning strategy a 40 $60 \%$ cost reduction, a complete measurability of the learning process and a standardized input and outcome of trainings has been achieved. This paper aims to highlight the impact of e-learning applied for business trainings within global developing companies. This study may be applicable to state education and thus could help to reduce the gap between local education and global expectations.
\end{abstract}

Keywords: e-learning, professional training, performance, globalization, standardization. 


\section{Introduction}

Fast growing markets, high product diversity and globalization offer great opportunities along with new challenges. Two major challenges are the increased necessity for standardization and the demand for fast achieved results in the learning industry.

A solution for a fast and standardized business knowledge transfer which allows obtaining control over the quality of information captured within the training sessions is given by the adoption of an effective e-learning strategy.

E-learning (electronic learning) is an embedded solution of knowledge subject matter expertise, instructional design and visual exemplifications that uses electronic technologies to deliver structured knowledge online to remote learners.

For Multinational Companies that have their Headquarter in one country and their operations in many others, cultural and knowledge differences represent one of the main issues of the human resources function (Wagner, 2014). According to the internationally collected data and studies (Cullen \& Parboteeah, 2014), e-learning is the primary means by which knowledge differences have been reduced as it allows engaging large volumes of learners into professional training programs. This impacted the learning industry itself and e-learning achieved a growth of approximately $900 \%$ in the last 15 years.

We have undertaken a research within Multinational Companies on the use of elearning programs in the field of developing professional trainings with the intention to question its impact on business.

\section{Research methodology}

To achieve the objectives, relevant research articles and literature were studied from trustful publishers and world-wide recognized professional associations and organizations. We recognized a common concern on the criteria of choosing to perform business trainings by use of e-Learning methodologies. Following, we analyzed the market trends and commercial environments where e-Learning has a high impact on the organizational development and found a correlation between theory and practice. Our empirical research was conducted by interviewing based on questionnaire 18 Multinational Companies from the top 50 Employers in Romania. Our scope was to identify the frequency on using eLearning and the criteria which counts most in their decision. Finally, we have compared the outcome of the literature review with the findings from the empirical analysis and answers of those interviewed.

\section{Research Environment}

As we nowadays witness, markets tend to merge as a result of companies struggling to optimize their business assets for best results and retain customers' loyalty. In the last 5 years in Romania, the main expansions and market mergers were produced by the telecom providers which added to their product and / or service portfolio television, banking through money transfer and different utility payments, and even power supply. 


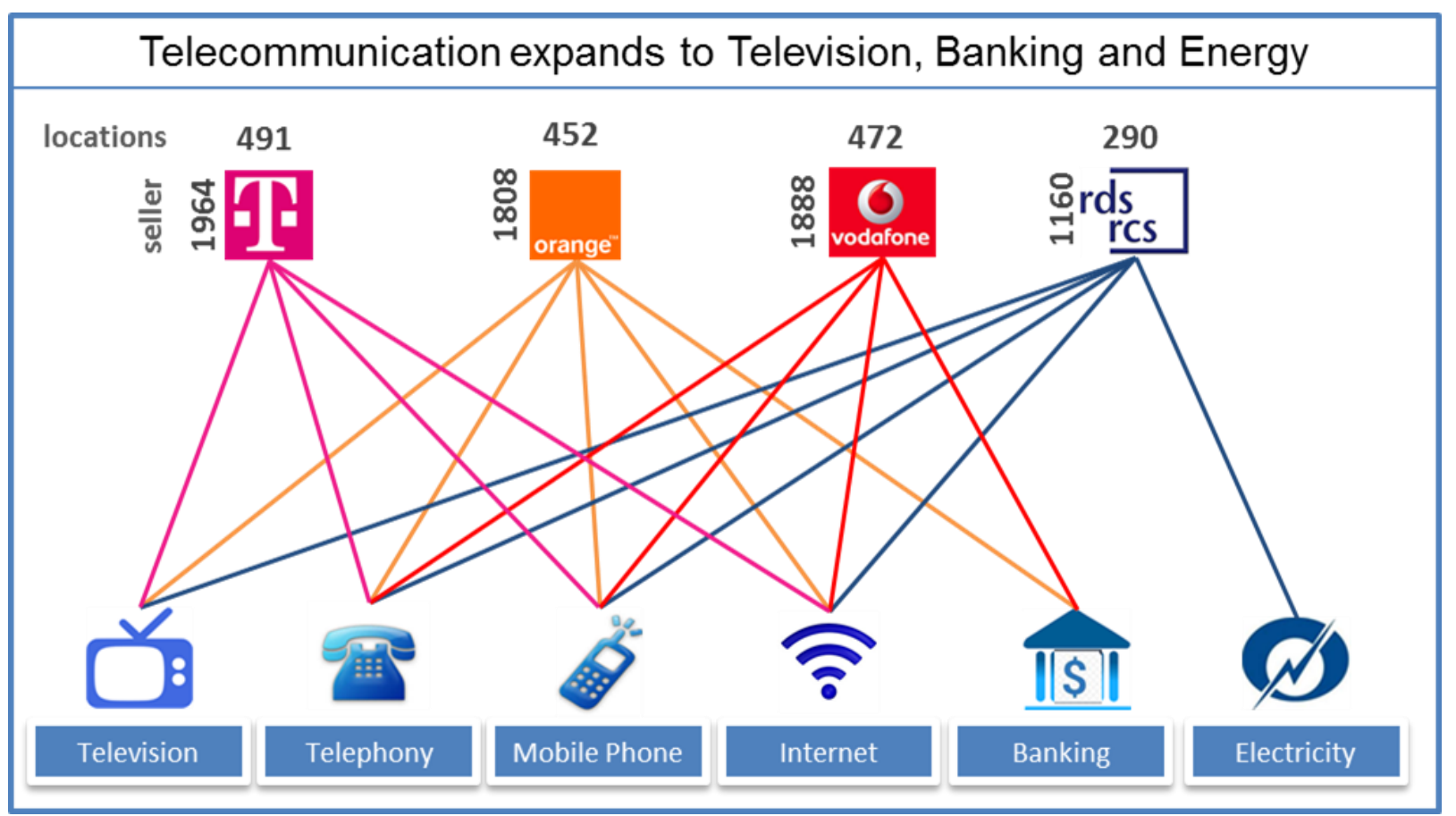

PICBE | 400

Figure 1. Telecommunication Companies expand to Television, Banking and Electricity markets in Romania

Source: Authors' own research results/contribution.

All product lines presented in Figure 1, make use of the companies' existing infrastructures, but require different understanding of business and management strategy. While many other skills evolved in a foreseen way, business understanding and knowledge faces a multitude of revolutionary changes making it a dynamic development area where continuous learning is essential for professional practitioners.

Due to the high confidentiality during the presale phase, there is a need to wait with the training of the staff until the very last minute; as per the information obtained within our research, not more than 10 days.

\section{Literature Review}

The scope of work of a training function within service providing companies

The success of a service providing Multinational Company depends on its capability to generate a high customer satisfaction. Marquardt et al. (2017) developed in "Study on the Development of Quality Measurements Models for Steering Business Services in Relation to Customer Satisfaction", a three level service quality model for defining the stages of customer satisfaction (p.104). 


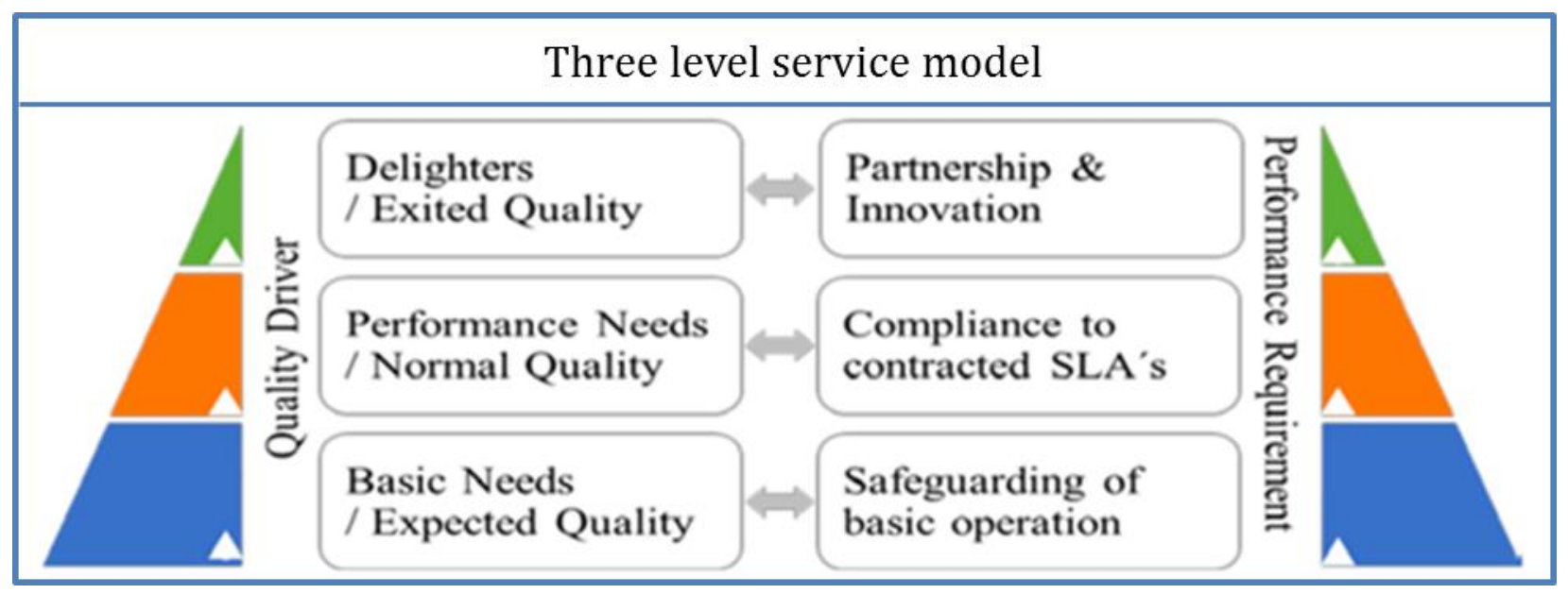

PICBE | 401

Figure 2. Three level service model

Source: http://www.amfiteatrueconomic.ro/RevistaDetalii_EN.aspx?Cod=1063

The first level represents the importance of a well-managed training function, by proving its impact on the business objective: "the fundamental (basic) level in each service operation is the safeguarding of the daily operation; therefore it is mandatory to have a functioning environment and the right amount of people with the right capabilities at the right time."

The major challenge in case of long term solutions is to ensure the governance of the agreement while leaving no option to failure. As well presented by Sarbu et al. (2016) in their research paper Governance as a Key Factor for Ensuring the Sustainability of Outsourcing Models: “...the change management framework and the innovation path must be carefully planned as during the years, the economic and social environment of a company will definitely change and if the contract is too rigid, the organization loses flexibility and adaptability" (p.473). A company's targets should change with its customers' needs and the market development. Therefore outsourced contracts have to offer enough flexibility to adapt to and manage changes for complying with the beneficiaries' internal process. As stated by Heinemann et al. (2016) in Study on international forms of cooperation for companies in the context of globalization "... by standardizing and optimizing cooperation from process perspective by the aid of modern communication and organization tools, efficiency and effectiveness can be increased" (p. 2426)

\section{E-learning classifications and tools}

The basic definition of e-learning is learning online. A detailed classification was done by Mayadas, Miller and Sener (2012) when they developed a set of definitions explaining elearning and its subclasses. In 2015, the definitions were updated and completed. According to their research, there are 6 different useful types of courses which include e-learning methods and tools. 


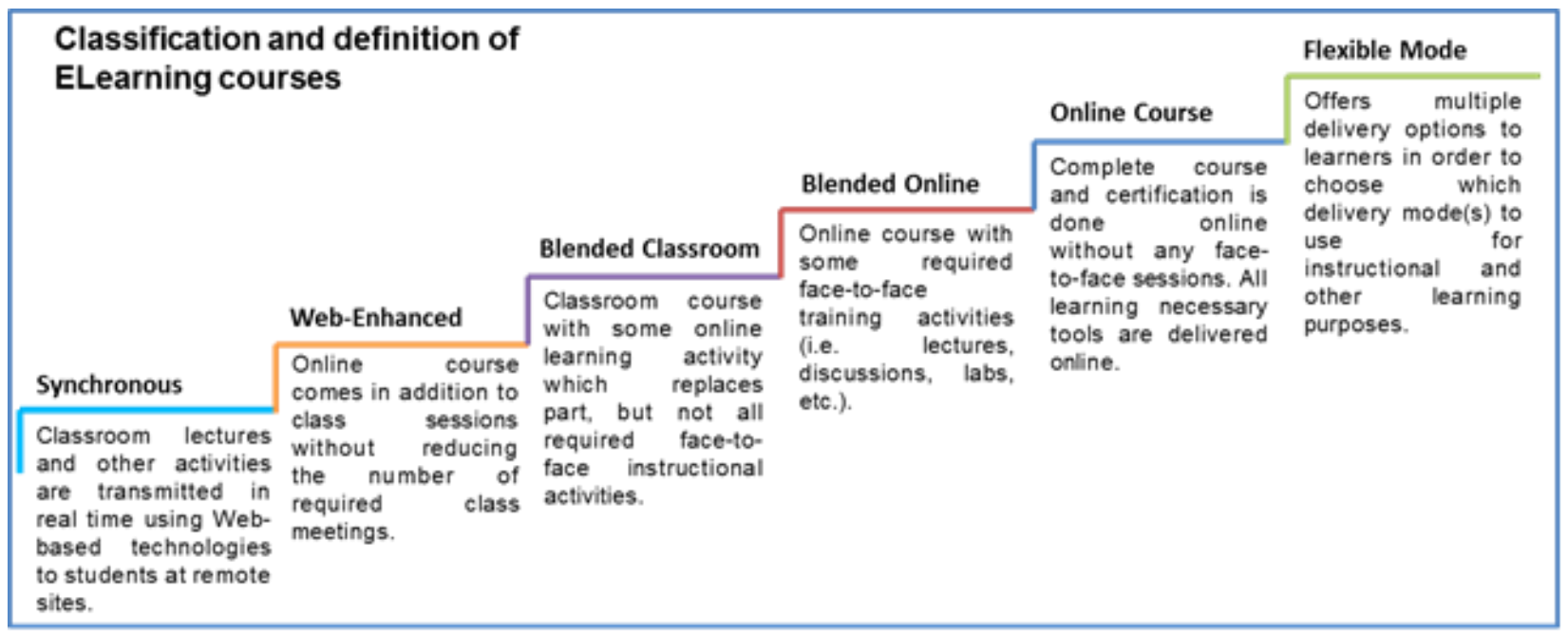

Figure 3. Classification and definition of e-learning courses

Source: Authors' own research results/contribution.

Figure 3 shows the 6 evolutionary steps of e-learning and describes typical types of application. Along with the development of the IT industry, multiple solutions for enhancing the delivery of e-learning courses were created together with the necessary infrastructure. Consequently, nowadays, E-learning courses include video interaction, animation, and trainee adaptive content flow. All these are embedded into a Learning Management System (LMS) which allows the trainer/teacher/organization to track the learning path of each engaged learner. This advanced tracking system highlights the interests as well as the difficulties and results of each participant during his individual online learning activity

Video-based learning was included into e-learning courses to offer learners an approach to a reality to which they did have no access before; through the details it can provide, video-based learning helps to internalize the information in the fastest possible way. A second advantage obtained by including video techniques like a video explanation or interview into an e-learning course is the connection it creates between the learner and his trainer. Several studies which were made to research and explain the impact of video based learning show that video inclusion is a mandatory premise for e-learning to deliver future outcomes. Those studies provide evidence that addressing of people from a frontal view enhances the retention of information and parasocial processes (Beege et al., 2017).

Both, video and animation, are extremely useful for producing an example-based learning environment (Roelle et al., 2017); it is a strategy to engage learners into topics with high levels of complexity, starting with processing simplest tasks and therefore making the transition easier (Aldrich, 2005; Roy, 2006).

Due to the high demand for e-learning, it has to fit to a large variety of learners which respond to different learning methods. Therefore, e-learning courses have to be designed as adaptive learning systems. Studies indicate that adaptive learning is a key factor in enhancing the learning performance of young learners (Chang et al., 2009).

A comprehensive overview of the various multimedia learning' aspects and its learning impact, including "how to" guidance was first edited by Richard E. Mayer for the University of California in 2005 and republished in an edited version in 2014. At that point in time the above mentioned multimedia tools and technics were at their beginnings and only guidelines to possible technical solutions could be drawn. Nevertheless, The 
Cambridge Handbook of Multimedia Learning represents a cornerstone, presenting comprehensive both, research and theory.

\section{Learning theories applied to e-learning}

The primary learning theory that applies best to e-learning courses is the constructivist theory. As recognized by Jean Piaget (n.d.), the learning development of a human is correlated to its learning environment and existing knowledge. E-learning is a proper tool for the constructivist theory as it has a high adaptability on learners' focus of interest. Compared to the traditional classroom training where information and learning materials are pushed to learners, E-learning uses pull principles, where learners manage the volume, quality and frequency of information they assimilate. Based on this, the learner's prior acquired knowledge determines the pace of the e-learning course or program. In this regard, as described in the Interactive Multimedia in E-learning 4, instruction plays a less important role in the learners' development (Misha; Ramesh, 2005; Schroeder; Spannagel, 2006)

\section{Cost of developing e-learning}

Paul Walliker undertook an explanatory comparison between e-learning and classroom courses for the Caterpillar University in 2005. One of the outcomes was that teaching through e-learning takes around $60 \%$ less time than the traditional way of transferring knowledge.

This significant time reduction has a massive impact on the cost calculation. And, attending traditional courses leads to further costs due to the long absence of the employees from their working place. Consequently most traditional trainings are spread over a long period of time enabling the company to handle the absence of the employees and the daily workload with the core workforce and without too much delay. This approach disengages the learner from the learning content and weakens the learning result of the course. We considered highlighting this aspect, because although there is usually no calculated value available, it might be a crucial argument to favor a specific learning method.

According to the above mentioned study, within a course in which minimum 100 learners are enrolled, e-learning wins the battle against classroom training with a saving of app. $40 \%$.

The highest reduction of costs due to e-learning can be expected with a number of participating learners starting from 2000 and constantly growing up to 5000; in this case a saving as high as app. $78 \%$ was calculated based on involved costs and research proven assumptions. After reaching this threshold, no further increase of the percentage cost reduction can be expected by using e-learning instead of traditional classroom courses. 


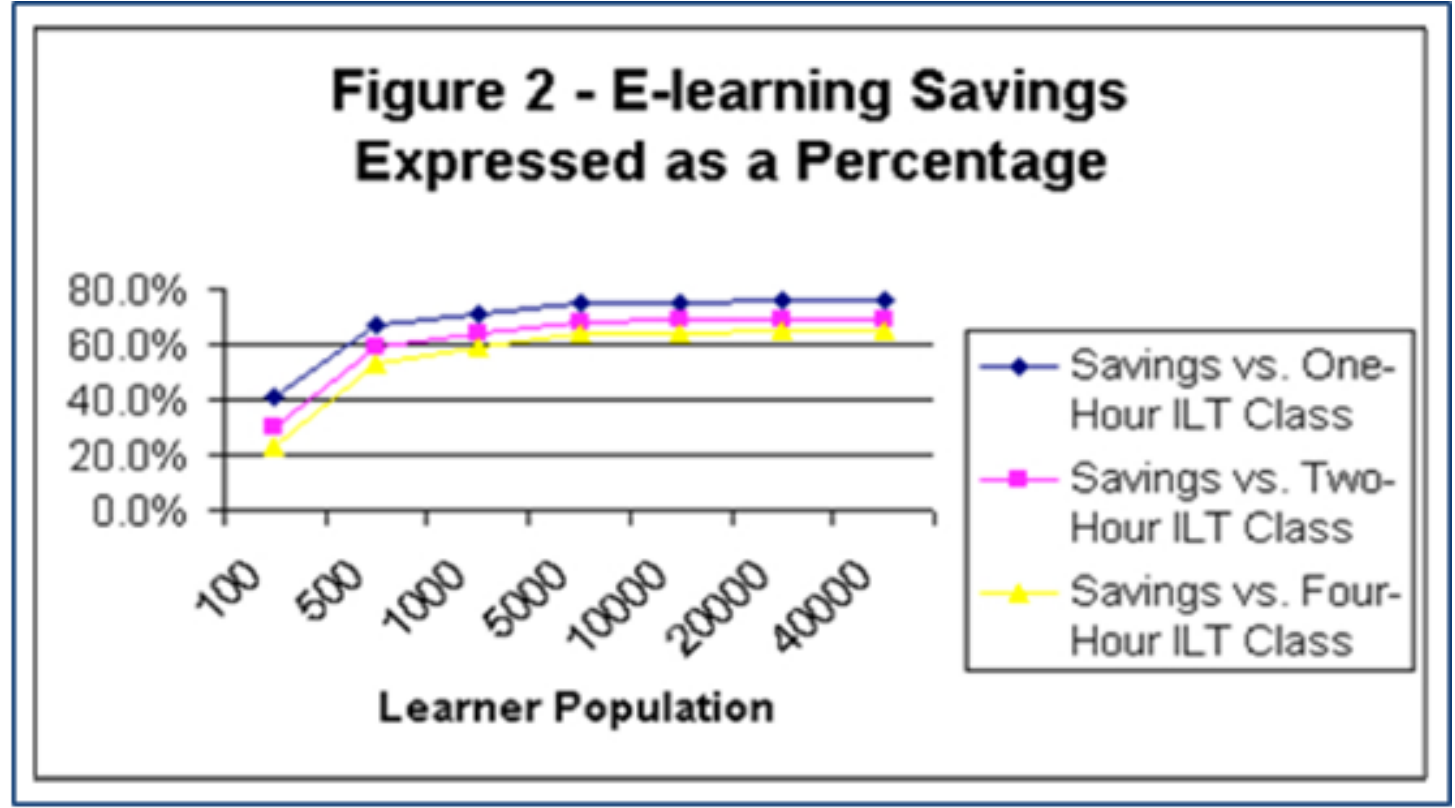

Figure 4. E-learning savings expressed as a percentage of the costs of classroom training

Source: Paul T. Walliker, Caterpillar University, 2005.

A comprehensive and updated study on this issue (Gipple, 2012) describes the necessary assets and the associated costs of an e-learning course and aims at a much lower number of participants.

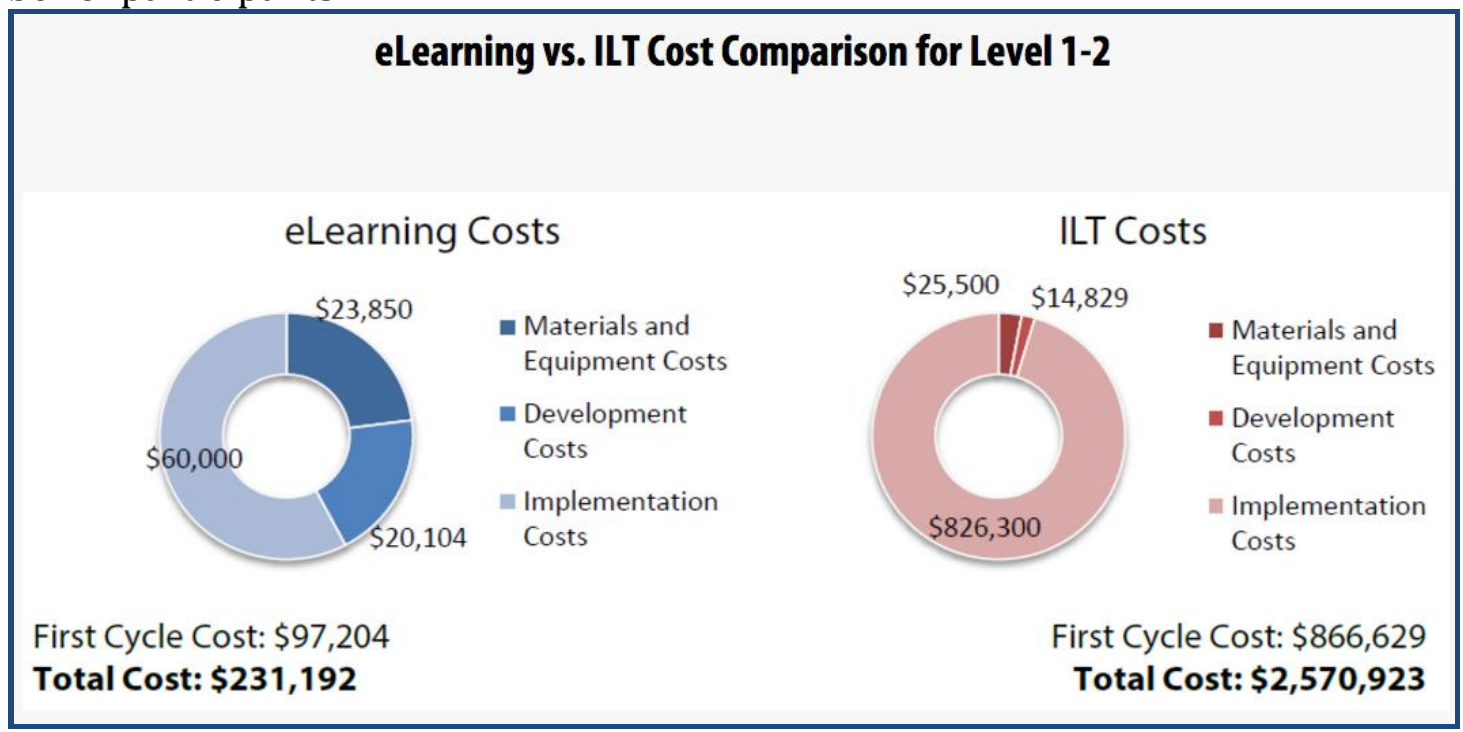

Figure 5. E-learning vs. ILT cost comparison

Source: www.icslearninggroup.com.

For developing an e-learning course of average quality and complexity, a mixture of professional skills, software and hardware is necessary.

A complete e-learning team should be formed of people from the following specialist areas:

- Instructional design;

- Graphical design

- Multimedia development IT engineering

The hard and software assets are a mix of: 
- Special configured computers;

- Licenses;

- Video infrastructure;

- Animation software;

- Storage and accessories and video, animation and sound libraries.

Thus the average cost of 1 hour e-learning course adds up to app. $€ 10.000$

The Return on Investment (ROI) of an e-Learning program is given by the formula:

$$
\mathrm{ROI}=\frac{\text { Benefits of Training }}{\text { Cost of Training }} \times 100
$$

To calculate the Cost-Benefit of an e-Learning program, besides the development and infrastructure costs, we have to take into consideration the Lost Production Time which represents the cost of the Company pays for the employee during his training session. This cost is calculated using the formula: number of employees $\mathrm{x}$ hourly rate $\mathrm{x}$ number of hours the training lasts.

Nevertheless, with the examined number of trainees and the given complexity of trainings its Return on Investment rate is significantly higher than that of classroom trainings.

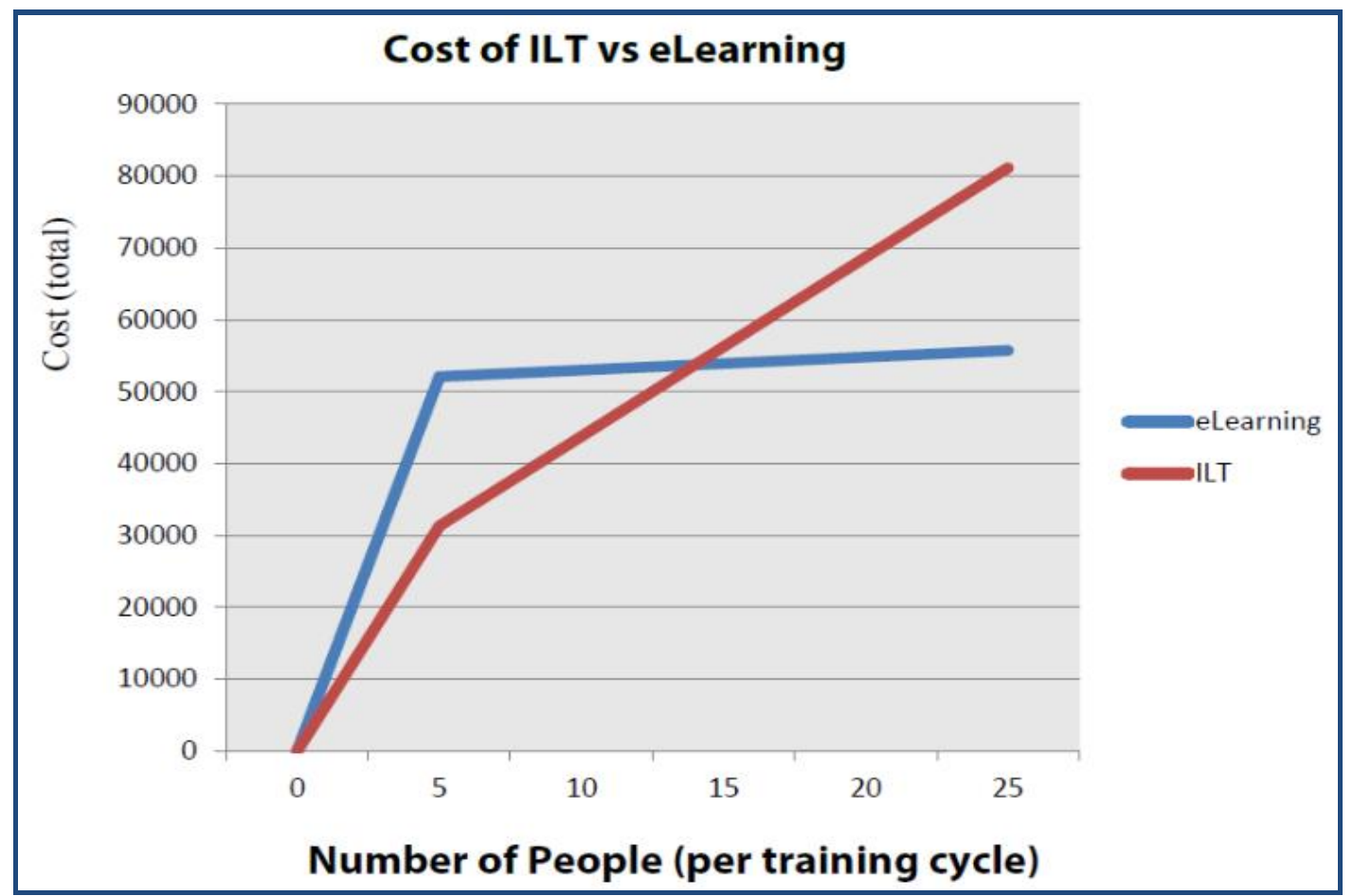

Figure 6. E-learning vs. ILT cost comparison

Source: www.icslearninggroup.com.

\section{Empirical Research \\ Context}

Within our empirical research, we identified developmental paths of the telecommunication market in Romania and applied theoretical findings described in the aforementioned chapter. Business development, as it was presented in Figure 1 is based on product and/or 
service diversification. This created an urgent need for internal training. The organizations started to work only with internal trainers who lacked certain skills, as until then, they had been more involved as internal course brokers and not been developed as trainers. The massive strategy change, which has been described in the explanations to Figure 1, and the necessity to keep the launch of new products and business fields confidential, as long as possible, urged the company to internally develop certain skills of their staff within an extremely short time frame.

\section{Case study}

Due to the confidentiality agreement we have signed, the identity of the company to which we refer will not be disclosed.

One of the Big 4 telecommunication providers in Romania was diversifying its product-line and merges to the banking sector, in their attempt to offer services as pay point for utility invoices, money transfer, payments to various online suppliers, etc. This new business line created the need to perform specialized training of the sales force in order to develop necessary skills for selling the new product. The internal training function had to provide effective training to over 1800 sales people in the shops spread across the country in over 400 locations.

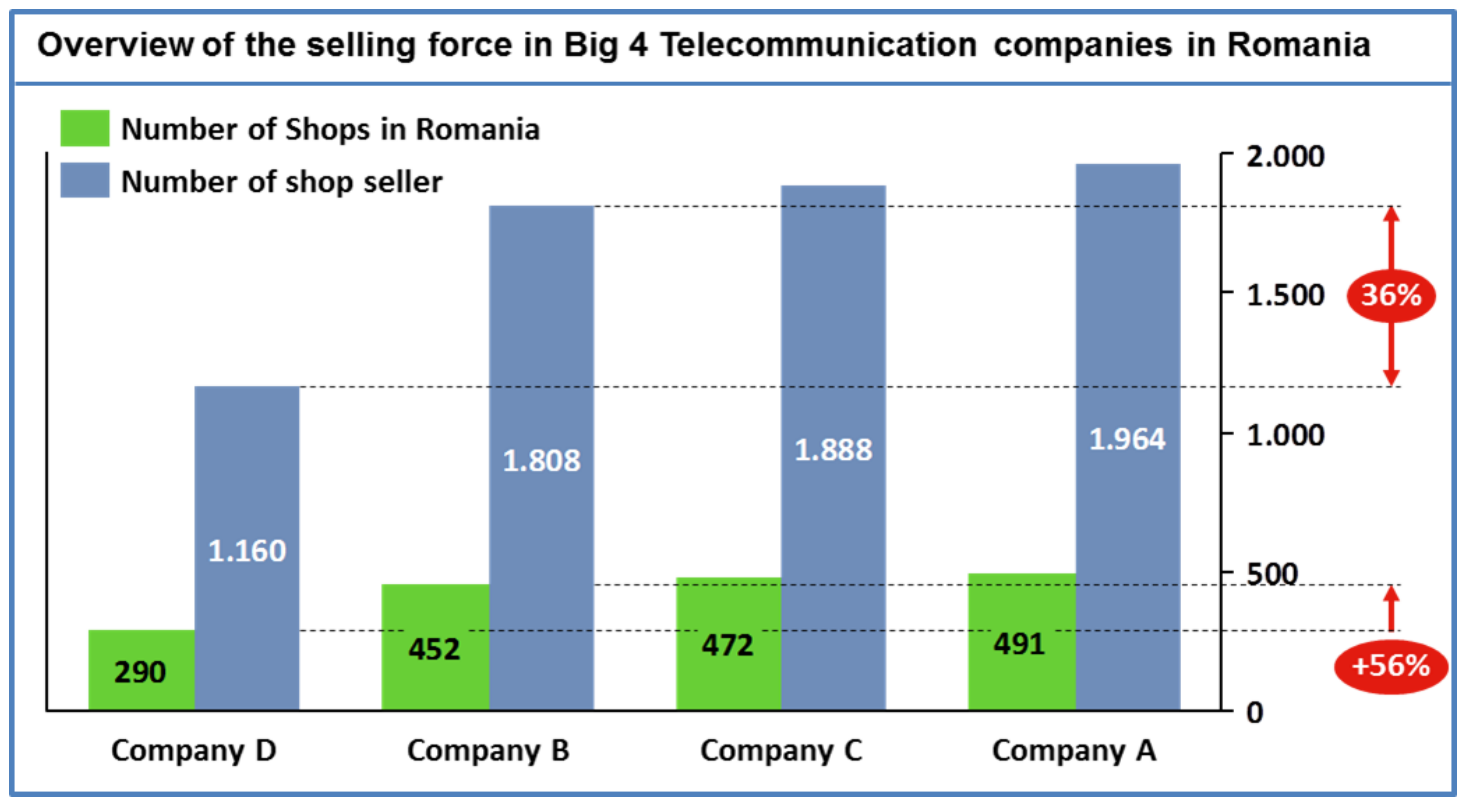

Figure 8. Overview of the selling force of big 4 Telecommunication companies in Romania

Source: Authors' own research results/contribution.

For accomplishing this major target, the learning plan included two steps: one for acquiring technical knowledge, including technical data of the process and risk/benefits analyzes. This approach shall ensure a better understanding of the process itself and create confidence in using special designed IT tools and applications to fulfill daily related tasks. The second step was defined to deliver information and advice on customer behavior and its buying decision of financial services.

Outsourcing the training to specialized providers was not possible, as the training had to cover confidential topics like internal marketing strategies, processes and key selling approaches. Thus, the pressure on the training organization was tremendous: within only 
two weeks all the sales people of the shops had to be instructed about the new market regulations and philosophies, technical data of the new products and the expected buyers' behavioral.

Having this situation, where 1800 employees from 400 locations had to be trained within 2 weeks on 2 different topics related to technical and soft skills, the only possible solution was developing e-learning programs. In this case, the decision was taken based on criteria as: time to competence, learning process control, full customized content and constant availability. Cost reduction was only a further advantage of the solution which showed its results later in time, when new employed salesman entered the process as a result of personnel fluctuation.

The overall cost of the program summed $€ 180,000$ and was delivered under a blended online solution. This means that all trainees went through the e-Learning program and were tested on their new acquired skills and knowledge. Additional to this, one salesman from each shop attended a classroom training session for a more detailed approach and open discussion. With the given cost difference and more than 1800 learners the training task has clearly a perfect dimension to design a blended online course. Based on the success of this project, the company plans to develop by 2020 half of its in-house trainings into online or blended online courses.

\section{Interview results}

Our questionnaire contains 8 questions, based on which we have interviewed 18 Multinational Companies, aiming to identify the companies familiarity with e-Learnings, what is the frequency of using it, the criteria based on which they decide whether they chose e-Learning or classroom training for different learning projects and what is their plan regarding further development of trainings into e-Learning programs. As the results shows, companies are more likely to choose an e-Learning solution, not of cost-saving reasons, as we presumed, but for the control over the process, availability and time savings. Cost saving seems to be the last advantage companies are looking for.

According to our calculations made within our research, a 2 weeks course held via elearning techniques equals app. 3.5 weeks of traditional classroom courses. By taking this into consideration, when a company as the one we build our case study on, is planning to develop $50 \%$ of internal skills into online courses or blended online, the time to competence of $50 \%$ of the training needs would be reduced with $43 \%$. 


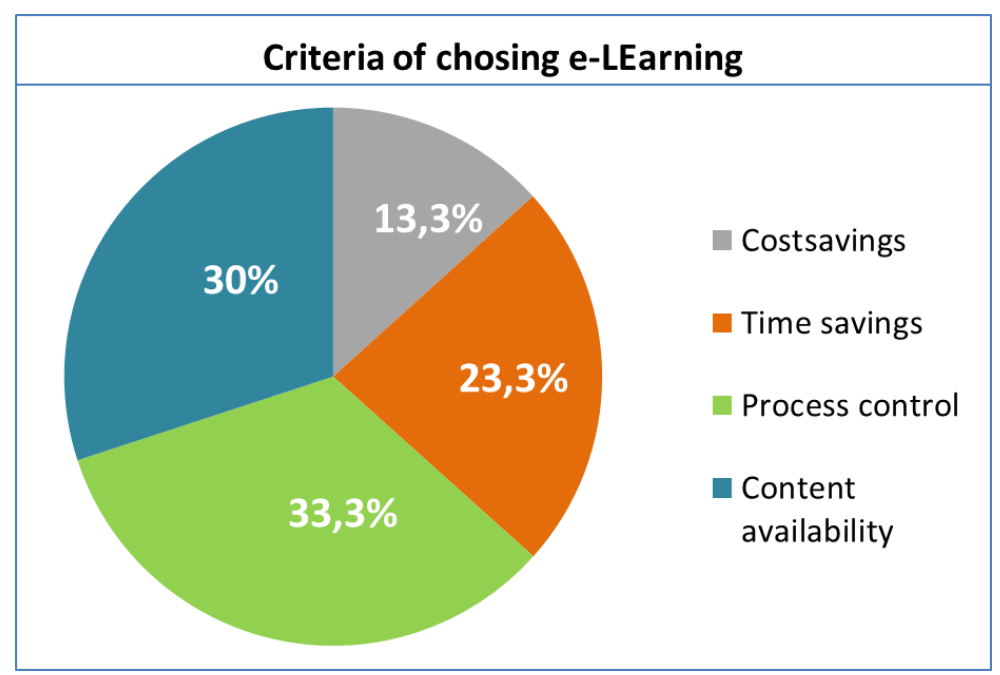

Figure 9. E-learning criteria of choosing e-Learning

Source: Authors' own research results/contribution.

\section{Conclusions}

From our research, it resulted that companies are more interested in gaining control over the learning process and content which they prefer having available at any time needed than looking after immediate cost savings. This approach delivers long lasting improvements as it offers flexibility in acquiring new skills. Consequently, besides complete process control, flexibility and availability over the training content, the company gains a huge advantage on the necessary time their employees needs for acquiring new skills. As per our example given, in the next 2 years, our sample company will reduce the time to competence of its employees with $43 \%$. This advantage can be translated into a higher responsivity towards market trends and changes and contribute to the business sustainability.

Another very helpful feature is the inclusion of videos in e-learning courses. It offers trainers the possibility to create a more "human" and "lifelike" training experience and improves the level of knowledge absorption of the trainees.

Besides the benefits of lifelike knowledge transfer, companies using videos and elearning obtain a standardized training outcome. Furthermore each trainee gains the flexibility to study the training subject whenever he is in need of or suitable to hi schedule, without leaving the workplace. This flexibility offers additional potential of cost savings.

\section{Bibliography}

Aldrich, C. (2005) Learning by Doing A Comprehensive Guide to Simulations, Computer Games and Pedagogy in e-Learning and Other Educational Experiences. Published by Pfeiffer, ISBN 978-07879-9735-1.

Aldrich, C. (2007) Simulations and the Future of Learning. Published by Pfeiffer, ISBN 9780787969622.

Allen, M. W. (2012) Leaving ADDIE for SAM: An Agile Model for Developing the Best Learning Experiences. Published by ASTD Press, ISBN 978-1-56286-711-9.

Allen, M. W. (2016) Michael Allen's Guide to e-Learning: Building Interactive, Fun and Effective Learning Programs for Any Company. Published by John Wiley \& Sons, Inc 
New Jersey, USA, ISBN 9781119046325.

Beege, M; Schneider, S; Nebel, S; Rey, G. D. (2017). Look into my eyes! Exploring the effect of addressing in educational videos; Learning and Instruction Volume 49, p.p. 113-120; http://dx.doi.org/10.1016/j.learninstruc.2017.01.004. Received 29 July 2016, Revised 4 January 2017, Accepted 13 January 2017, Available online 22 January 2017.

Clark, R. C.; Mayer, E. R. (2016). E-Learning and the Science of Instruction. Proven Guidelines for Consumers and Designers of Multimedia Learning, Fourth Edition. Published by John Wiley \& Sons, Inc. ISBN 9781119158660.

Cullen, J. B.; Parboteeah, P. K. (2014) Multinational Management: A Strategic Approach, 6e. Published by Cengage Learning, ISBN 978-1-285-09494-6.

Chang, Y. C., Kao, W. Y., Chu, C. P., \& Chiu, C. H (2009). A learning style classification mechanism for e-learning. Published in Computers and Education Journal, Vol. 53(2), p.p. 273-285; DOI: 10.1016/j.compedu.2009.02.008.

Clark, R.C.; Nguyen, F. \& Sweller, J. (2006). Efficiency in Learning: Evidence-Based Guidelines to Manage Cognitive Load. San Francisco: Pfeiffer. ISBN 0-7879-7728-4.

Gipple, J. (2012). Is e-learning Worth it? e-learning Cost Analysis. Published by ICS Learning Group, 410-975-9440; www.icslearninggroup.com.

Hattie, J. (2009) Visible Learning A Synthesis of over 800 Meta-Analyses Relating to Achievement. Published by Routledge, ISBN 978-0-415-47618-8;

Halls, J. (2012) Rapid Video Development For Trainers. Published by ASTD Press, ISBN 9781-56286-811-6.

Heinemann, B.; Floricel, T.; Gavril, R.; Golowko, N. (2016) Study on the international forms of cooperation in the context of globalization. 27th International Business Information Management (IBIMA) Conference, IMEEV, 5/4/2016. Innovation Management and Education Excellence Vision 2020, p.p. 2418-2427, ISSN, ISBN 978 0-9860419-6-9.

Wagner, T. (2010). The Global Achievement Gap. Revised edition published 2014 by Basic Books, Persus Books Group, ISBN 978-0-465-05596-8.

Marquardt, K., Olaru, M. and Ceausu, I. (2017). Study on the Development of Quality Measurements Models for Steering Business Services in Relation to Customer Satisfaction. Amfiteatru Economic, Volume 19(44), p.p. 95-109. http://www.amfiteatrueconomic.ro/RevistaDetalii_EN.aspx?Cod=1063.

Mateiu, A., Mateescu, R. M., Buchmüller, M., Just, V. (2016) Governance as a key factor for ensuring the sustainability of outsourcing models, Conference ISI Proceedings, The 4th International Conference on Management, Leadership and Governance (ICMLG 2016), p.p. 466-474, ISBN: 978-1-910810-84-2, Paper in progress of being indexed in ISI Web of Knowledge.

Mayadas, F; Miller, G; Sener, J. (2015) Definitions of E-Learning Courses and Programs Version 2.0, https://online-learningconsortium.org/updated-e-learning-definitions-2/ Presented within the $21^{\text {st }}$ Annual Online Learning Consortium International Conference 2015; http://olc.online-learningconsortium.org/conference/2015/aln/definitions-elearning-courses-and-programs-conversation.

Mayer R. E. (2009) Multimedia Learning, $2^{\text {nd }}$ edition. Published by Cambridge University Press, ISBN 978-0-521-73535-5.

Mayer R. E. (2014) The Cambridge Handbook of Multimedia Learning. $2^{\text {nd }}$ edition. Published by Cambridge University Press, ISBN 978-1-107-61031-6. 
Meyer, L. D. (2009). "The Poverty of Constructivism". Educational Philosophy and Theory. Volume 41(3) p.p. 332-341. doi:10.1111/j.1469-5812.2008.00457.x.

Mishra, S.; Ramesh, S. C. (2005). Interactive Multimedia in Education and Training. Published by Idea Group Publishing, ISBN 1-59140-393-6.

Phillips, P.; Phillips, J.; Ray, R. (2015). Measuring the Success of Leadership Development. A Stepby-Step Guide for Measuring Impact and Calculating ROI. Published by: ATD Press, ISBN 978-1-56286-942-7.

Roelle, J; Hiller, S; Berthold, K; Rumann, S (2017) Example-based learning: The benefits of prompting organization before providing examples, DOI: 10.1016, Learning and Instruction, 2017, Volume 49, p.p. 1-12, ISSN 0959-4752, PUB-ID 2908371.

Roy, K. (2006). The impact of learning styles on interactivity in asynchronous e-learning. Published online in Wiley Intersience DOI:10.1002/pfi026; International Society for Performance Improvement, Volume 45(10), p.p. 21-26.

Schroeder, U.; Spannagel, C. (2006). Supporting the Active Learning Process. International Journal on E-learning, Volume 5(2) Published by: Association for the Advancement of Computing in Education (AACE), ISSN 1537-2456.

Wagner, T. (2010). The Global Achievement Gap. Revised edition published 2014 by Basic Books, Persus Books Group, ISBN 978-0-465-05596-8.

Walliker, P. T. (2005). Cost comparison: Instructor-led vs. e-learning. LearningCircuits, (June),http://ciofs.net/fad/auxilium/af_06-

07/amdel/materialidocenti/ercole/cost_comparison_instructor_led_vs_elearning.pdf. 